\title{
To revascularize or not to revascularize: a dilemma in heart failure
}

\section{Roxy Senior}

$\infty$

See related article page $36 \mathrm{I}$

I $\mathrm{n}$ developed nations, the leading cause of heart failure is coronary artery disease. ${ }^{1}$ Established treatment options for ischemic heart failure include medical therapy, revascularization and cardiac transplantation. Cardiac resynchronization therapy has been recently introduced as a treatment modality for heart failure, but other modalities remain investigational. ${ }^{2}$ Despite therapeutic advances, outcomes of medical therapy in severe heart failure remain poor. ${ }^{1,3}$ For many categories of patients, the potential benefits of revascularization must be weighed against its high periprocedural risks.

Randomized controlled trials of coronary revascularization in patients with heart failure have yet to be completed. Because of the paucity of data from contemporary therapies, practice decisions are largely based on surgical studies performed nearly 2 decades ago. In the 2 largest retrospective series, the Coronary Artery Surgery Study registry (420 medical and 23I surgical patients) ${ }^{4}$ and the Duke University Cardiovascular Database (409 medical and 301 surgical patients), ${ }^{5}$ a significant long-term survival advantage has been observed for CABG over medical therapy, but the surgical survival benefits have been greatest for those patients with the severest left-ventricular (LV) systolic dysfunction (LV ejection fraction [LVEF] $<25 \%$ ), most extensive coronary-artery disease and most intense angina. Although results from these and other smaller studies overall favoured surgery over medical therapy, important limitations have included selection bias for revascularization, inadequate medical therapy in both medical and surgical groups, use of surgical techniques now outdated ${ }^{6}$ and small numbers of patients, particularly of patients whose symptoms are predominantly those of heart failure.

Perioperative mortality rates for coronary-artery bypass grafting (CABG) in patients with LV systolic dysfunction vary widely, from about $5 \%$ among younger adults to more than $30 \%$ among older people, who have more severe LV systolic dysfunction and comorbidities. ${ }^{7}$ Similarly, exclusive PTCA (percutaneous transluminal coronary angioplasty) in patients with LV systolic dysfunction is associated with a high periprocedural rate of death $(2.5 \%-5 \%)$. In a report ${ }^{8}$ of registry data from before stents came into use, $18.2 \%$ of patients with LVEFs of $25 \%-35 \%$ experienced nonfatal myocardial infarction and acute closure.

The article by Tsuguki and colleagues ${ }^{9}$ in this issue is a retrospective analysis in which they compared the rate of death among patients with heart failure treated with revascularization with that among those treated with medical therapy, irrespective of myocardial viability. This report displays the same limitations as previous observational studies. Furthermore, although the authors have adjusted for clinical variables,

most of the revascularizatons were undertaken not because of symptoms of heart failure but rather those of acute coronary syndrome. In deed, only $7.7 \%$ of the patients underwent cardiac catheterization because of heart-failure symptoms. The study reflected patients studied in 1995-2000. Because both medical therapy and revascularization procedures have improved considerably in the last few years, the treatment modalities they experienced are unlikely to mimic the state-ofthe-art treatments patients currently are likely to receive. In this study, fewer than half of the patients were taking angiotensin-converting enzyme (ACE) inhibitors or angiotensin blockers; only one-third were taking $\beta$-blockers; and none were taking spironolactone. The report does not clarify whether stents were placed into any members of the percutaneous revascularization group. \section{Perioperative death rates for CABG can exceed 30\% among older patients.}

Although published retrospective series have alluded to the potential survival benefits of revascularization in heart failure, limitations in study design and higher periprocedural risk have created uncertainty about the optimal treatment strategy. This provides a rationale for noninvasive testing for myocardial viability in patients with LV systolic dysfunction, which, although based mainly on findings from observational studies, has potential value before revascularization in cases of moderate to severe ischemic cardiomyopathy. Several studies have assessed medium-term death rates among patients who were managed medically or with revascularization after testing for myocardial viability by means of positron- or single-photon emission CT and dobutamine echocardiography. ${ }^{10-12}$ Death rates were relatively high in all groups except patients with hibernating myocardium who underwent revascularization. A meta-analysis ${ }^{13}$ of 24 nonrandomized studies found that $3.2 \%$ of patients with myocardial viability who had revascularization died, compared with $17 \%$ of those who were treated with medical therapy - an $80 \%$ relative reduction in mortality $(p<0.001)$, accompanied by a collective $51 \%$ relative reduction in other adverse events. The difference in benefit when viability was absent $(6.2 \%$ v. $7.7 \%)$ was not statistically significant. When the meta-analysis was limited to the 9 
studies with sufficient data to calculate the odds ratio for treatment-viability interaction, ${ }^{14}$ revascularization still had a greater effect on long-term rate of death than medical therapy in patients with viable myocardium, although the magnitude of the effect in the subgroup was far lower than for the larger cohort.

The main shortcoming of these studies is that they were retrospective and observational. Clearly, prospective randomized studies are needed to obtain definitive conclusions on the prognostic value of revascularization in patients with heart failure. Two major randomized, prospective studies are underway to compare revascularization and medical therapy in the treatment of heart failure, involving patients whose predominant symptom is breathlessness. The intention in the Surgical Treatment in Ischemic Heart Failure trial (STICH), a global trial being conducted in the United States, is to randomly assign 1600 patients to receive either medical therapy alone or revascularization along with medical therapy. ${ }^{15}$ Evidence of myocardial viability forms no part of the trial's inclusion or exclusion criteria, although those data are being collected. A UK study, on the other hand - the Heart Failure Revascularization Trial (HEART) - randomly assigns patients with evident myocardial viability into the 2 groups. ${ }^{16}$

In conclusion, uncertainty remains as to whether revascularization of patients with heart failure and coronary artery disease is safe or beneficial, even when myocardial viability is present. Findings from the STICH and HEART trials will help address these questions.

Roxy Senior is with the Department of Cardiovascular Medicine, Northwick Park Hospital and Institute for Medical Research, Harrow, Middlesex, UK

Competing interests: None declared.

\section{REFERENCES}

I. The Study Group on Diagnosis of the Working Group on Heart Failure of the European Society of Cardiology. Increasing awareness and improving the managemen of heart failure in Europe: the Improvement of HF initiative. Eur J Heart Fail I999; I:I39-44.

2. Melo LG, Pachori AS, Kong D, et al. Molecular and cell-based therapies for protection, rescue, and repair of ischemic myocardium: reasons for cautious optimism. Circulation 2004;109:2386-93.

3. Cleland JG, Pennell DJ, Ray SG, et al. Myocardial viability as a determinant of the ejection fraction response to carvedilol in patients with heart failure (CHRISTMAS trial): randomized controlled trial. Lancet 2003;362:14-21.

4. Alderman E, Fisher LD, Litwin P, et al. Results of coronary artery surgery in patients with poor left ventricular dysfunction (CASS). Circulation $1983 ; 68: 785-95$.

5. Bounous EP, Mark DB, Pollock BG, et al. Surgical survival benefits for coronary disease patients with left ventricular dysfunction. Circulation I988;78:115I-7.

6. Krishnamani R, El-Zaru M, DeNofrio D. Contemporary medical, surgical, and device therapies for end-stage heart failure. Curr Treat Options Cardiovasc Med 2003;5:487-99.

7. Baker DW, Jones R, Hodges J, et al. Management of heart failure. III. The role of revascularization in the treatment of patients with moderate or severe left ventricular systolic dysfunction. JAMA 1994;272:1528-34.

8. Holmes DR Jr, Detre KM, Williams DO, et al. Long-term outcome of patients with depressed left ventricular function undergoing percutaneous transluminal coronary angioplasty; the NHLBI PTCA registration. Circulation I993;87:2I-9.

9. Tsuyuki RT, Shrive FM, Galbraith PD, et al; for the APPROACH Investigators Revascularization in patients with heart failure. CMAJ 2006;175(4):36I-5.
Io. Eitzman D, Al-Aouar ZR, Kanter HL, et al. Clinical outcome of patients with advanced coronary artery disease after viability studies with positron emission tomography. J Am Coll Cardiol 1992;20:559-65.

II. Pagley PR, Beller GA, Watson DD, et al. Improved outcome after coronary bypass surgery in patients with ischemic cardiomyopathy and residual myocardial viability. Circulation 1997;96:793-800.

I2. Senior R, Kaul S, Lahiri A. Myocardial viability on echocardiography predicts longterm survival after revascularisation in patients with ischemic congestive heart failure. J Am Coll Cardiol I999;33:I848-54.

13. Allman KC, Shaw LJ, Hachamovitch R, et al. Myocardial viability testing and impact of revascularization on prognosis in patients with coronary artery disease and left ventricular dysfunction: a metal-analysis. J Am Coll Cardiol 2002;39:II5I-8.

I4. Bourque JM, Hasselblad V, Velazquez EJ, et al. Revascularization in patients with coronary artery disease, left ventricular dysfunction, and viability: a meta-analysis. Am Heart J 2003; I46:62I-7.

I5. STICH investigators. Comparison of surgical and medical treatment for congestive heart failure and coronary artery disease [official study title: Surgical Treatment for Ischemic Heart Failure (STICH)]. Available: www.clinicaltrials.gov/ct/gui/show /NCTooo23595 (accessed 2006 Jul I3).

I6. Cleland JG, Freemantle N, Ball SG, et al. The Heart Failure Revascularisation Trial (HEART) rationale, design and methodology. Eur J Heart Fail 2003;5:295-303.

Correspondence to: Dr. R. Senior, Consultant Cardiologist and Director of Cardiac Research, Department of Cardiovascular Medicine, Northwick Park Hospital, Watford Road, Harrow, Middlesex UK HAI 3UJ; 44208869 2547; fax 44208864 0075; roxysenior@cardiac-research.org

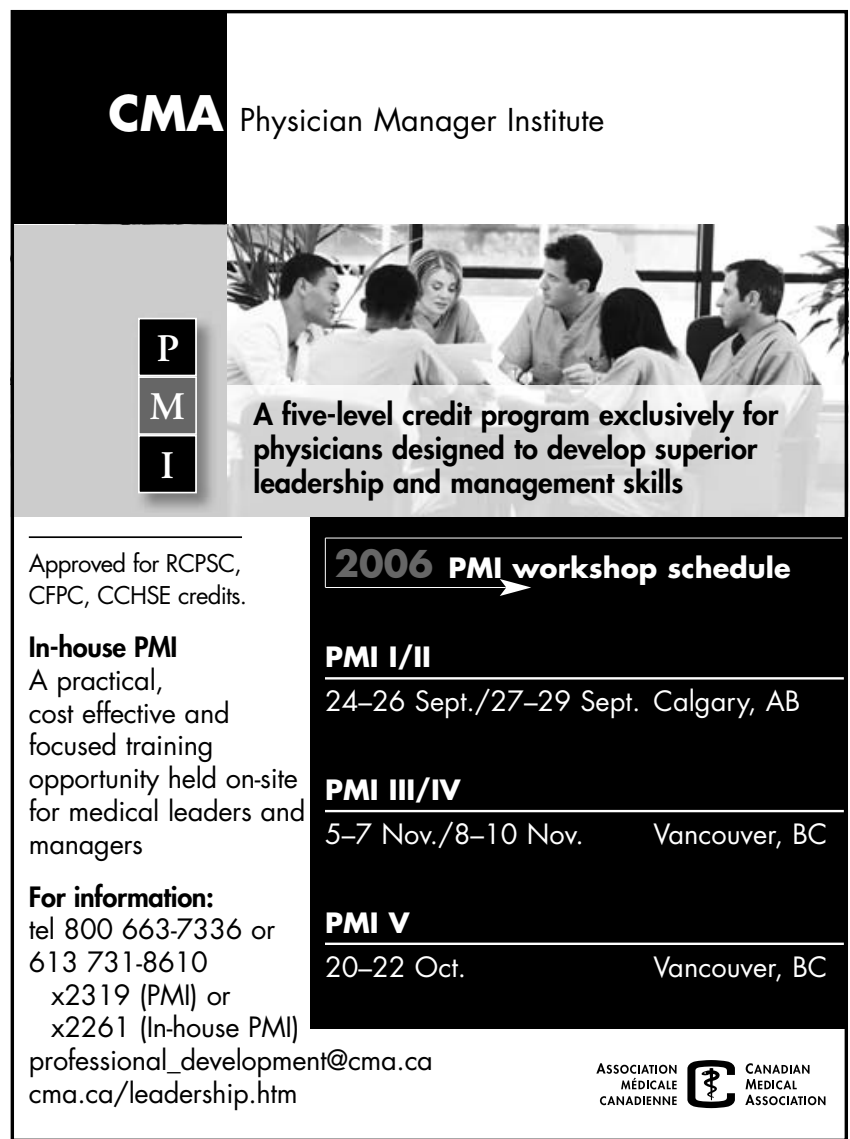

